\title{
De Novo Erythroleukemia Chromosome Features Include Multiple Rearrangements, With Special Involvement of Chromosomes II and I9
}

\author{
Juan C. Cigudosa, ${ }^{1 *}$ Maria D. Odero, ${ }^{2}$, M. José Calasanz, ${ }^{2}$ Francesc Solé, ${ }^{3}$ Marta Salido, ${ }^{3}$ Eva Arranz, ${ }^{4}$ \\ Angel Martínez-Ramirez,' Miguel Urioste,' Sara Alvarez,' Jose V. Cervera, ${ }^{5}$ Donald MacGrogan, ${ }^{6}$ \\ Miguel A. Sanz, ${ }^{5}$ Stephen D. Nimer, ${ }^{6}$ and Javier Benitez' \\ 'Cytogenetics Unit, Department of Human Genetics, Spanish National Cancer Center, Madrid, Spain \\ ${ }^{2}$ Department of Genetics, University of Navarra, Pamplona, Spain \\ ${ }^{3}$ Laboratory of Cytology, Department of Pathology, Hospital del Mar, IMAS, IMIM, Barcelona, Spain \\ ${ }^{4}$ Service of Hematology, Hospital La Princesa, Madrid, Spain \\ ${ }^{5}$ Service of Hematology, Hospital La Fe, Valencia, Spain \\ ${ }^{6}$ Laboratory of Molecular Aspects of Hematopoiesis, Memorial Sloan-Kettering Cancer Center, New York, NY
}

Erythroid leukemia (ERL or AML-M6) is an uncommon subtype of acute myeloid leukemia, the clinical, morphological, and genetic behavior of which needs further characterization. We analyzed a homogeneous group of 23 de novo AML-M6 patients whose bone marrow cells showed complex karyotypes. We also analyzed eight leukemia cell lines with erythroid phenotype, performing detailed molecular cytogenetic analyses, including spectral karyotyping (SKY) in all samples. The main features are: (I) A majority of patients (56\%) had hypodiploidy. Loss of genetic material was the most common genetic change, especially monosomies of chromosome 7 or 18, and deletions of chromosome arm 5q. Taken together, 87\% of the cases displayed aberrations involving chromosome 5 or 8 . (2) We describe a novel, cryptic, and recurrent translocation, $\mathrm{t}(\mathrm{II} ; \mathbf{9}$ ) $(\mathrm{pl}|\mathrm{I} .2 ; \mathrm{q}| 3 . \mathrm{I})$. Another translocation, $\mathrm{t}(\mid 2 ; 2 \mathrm{I})(\mathrm{p}|\mathrm{I} .2 ; q| \mathrm{I} .2)$, was found to be recurrent in a patient with $\mathrm{ERL}$ and in the K562 cell line. (3) MLL gene rearrangements were detected in $20 \%$ of cases (three translocations and three amplifications) and, overall, we defined 52 rearrangements (excluding deletions) with a mean of 2.3 translocations per patient. (4) Of the structural aberrations, $21 \%$ involved chromosomes II and 19. Most of the rearrangements were unbalanced; only I 3 reciprocal translocations were observed. The general picture of chromosomal aberrations in cell lines did not reflect what occurred in patient samples. However, both primary samples and cell lines shared three common breakpoints at $19 q|3.1,20 q| I .2$, and 2 Iql I.2. This is the first molecular cytogenetic description of the karyotype abnormalities present in patients with ERL. It should assist in the identification of genes involved in erythroleukemogenesis.

(c) 2003 Wiley-Liss, Inc.

De novo erythroleukemia (ERL) is a rare type of acute myeloid leukemia (AML), representing $2-7 \%$ of de novo AML cases. Because of its heterogeneous nature, ERL has posed difficulties in its precise classification. Most authors agree that two main subtypes exist, according to the WHO classification of acute erythroid leukemias: (1) erythroleukemia (erythroid/myeloid), M6 acute leukemia according to the FAB criteria, in which mixed granulocytic ( $>20 \%$ myeloblasts) and erythroblastic cellular components are present; and (2) pure erythroid leukemia with erythroblasts constituting more than $80 \%$ of the marrow cells, with no significant myeloblastic component (Bennett et al., 1985; Goldberg et al., 1998; Mazzella et al., 1998; Jaffe et al., 2001; Domingo-Claros et al., 2002; Park et al., 2002).

In contrast to other types of acute leukemia, no specific cytogenetic or molecular markers are available for ERL for classification or prognostic pur- poses (Cuneo et al., 1990; Olopade et al., 1992; Kwong, 1998). About $70 \%$ of de novo ERL cases show chromosome abnormalities (Cuneo et al., 1990; Olopade et al., 1992; Goldberg et al., 1998). In fact, 378 different abnormal karyotypes have been recorded in the Mitelman Database of Chromosome Aberrations in Human Cancer (http:// cgap.nci.nih.gov/Chromosomes/Mitelman) (Mitelman et al., 2002). Other than a high frequency of loss or partial deletions of chromosomes 5 and/or 7 ,

\footnotetext{
Supported by: Spanish Ministry of Science and Technology; Grant number: SAF-2001-0056.

A. Martínez-Ramirez is a fellow of the Carlos III Institute, Madrid, Spain.

*Correspondence to: Juan C. Cigudosa, Cytogenetics Unit, Centro Nacional de Investigaciones Oncologicas, Melchor Fernandez Almagro, 3. 28029 Madrid, Spain. E-mail: jccigudosa@cnio.es Received 25 July 2002; Accepted 6 November 2002 DOI 10.1002/gcc.10180
} 
or trisomy 8 , which are commonly found in myelodysplasias and several subgroups of AML, specific genetic abnormalities have not been recurrently found in ERL. The most commonly identified karyotypes in ERL reflect a great complexity (frequently with more than three rearrangements), and a lack of recurrent breakpoints (other than those affecting chromosome 5 or 7). More powerful molecular cytogenetic tools are now available, such as fluorescence in situ hybridization (FISH), comparative genomic hybridization (CGH), and spectral karyotyping (SKY), which can help in identifying the genetic changes that take place in ERL. We used molecular cytogenetics to study a series of homogeneously defined de novo ERLs, with complex karyotypes, as well as eight erythroid leukemia cell lines. We found several recurring distinctive and novel genetic features of this subtype of leukemia.

We studied 23 patients, 10 male and 13 female, whose ages ranged from 1 to 85 years, with a median of 69 years. All samples were collected at diagnosis. The clinical history of previous hematologic disorders and/or chemotherapy or exposure to other known genotoxic agents was ruled out in every case. Morphological classification criteria were applied according to the WHO proposal (Jaffe et al., 2001). Erythroleukemia (erythroid/myeloid) was defined by the presence of $\geq 50 \%$ erythroid precursors in the entire nucleated cell population and $\geq 20 \%$ myeloblasts in the non-erythroid population; pure erythroid leukemia: $>80 \%$ of marrow cells of the erythroid lineage with no evidence of a significant myeloblastic component. All slides were reviewed centrally by some of the authors. We also analyzed eight leukemia cell lines with erythroid phenotype, irrespective of the type of leukemia from which they were derived. Five cell lines were derived from chronic myeloid leukemia (CML) in blast crisis, SAM-1 (provided by J. Cossman), AP217 (provided by R. Berthier), K-562 (in-house), HEL-R (provided by T. Papayannnopoulou), and LAMA 84 and KU812 (provided by J. Goldman). Two cell lines were derived from AML-M6: KMOE-2 (from the Deutsche Sammlung von Mikroorganismen und Zellkulturen, Germany) and TF-1 (in-house). The cells lines were cultured, according to their respective requirements, and they were harvested after $2 \mathrm{hr}$ of exposure to Colcemid, for standard cytogenetic procedures.

All samples had a complex aberrant karyotype at diagnosis. We considered a karyotype complex when three or more clonal chromosome abnormalities were identified. Conventional cytogenetics was performed on bone marrow samples after direct and/or short-term culture without mitogens. Metaphase cells were prepared from all samples. G-banding analysis was performed by standard procedures. Karyotypes were described according to the ISCN (Mitelman, 1995). After conventional cytogenetic analysis, slides were prepared from the fixative-stored material and hybridized using the SKY method according to the manufacturer's protocol (Applied Spectral Imaging, Migdal Ha-Emck, Israel). Images were acquired with an SD300 Spectra cube (Applied Spectral Imaging) mounted on a Zeiss Axioplan microscope using a custom-designed optical filter, SKY-1 (Chroma Technology, Brattleboro, VT). For each case, 8-30 metaphase cells were captured and analyzed. Breakpoints corresponding to the chromosome abnormalities were assigned based on the corresponding DAPI banding and G-banded karyotype of the same cells. An abnormality or breakpoint was considered as recurrent if it was identified in two or more different cases by G-banding or SKY. A whole chromosome painting (WCP) probe for chromosome 19, telomeric $19 \mathrm{p}$ and $19 \mathrm{q}$ FISH probes (Appligene Oncor, France), and $B C R / A B L$ and $M L L$ FISH probes ( $\mathrm{Vy}-$ sis, Downers Grove, IL) were used to define the involvement of these genes or chromosome regions. Hybridizations were performed according to the manufacturer's protocols.

All 23 patients were selected based on their fulfillment of the WHO criteria for ERL and the presence of complex karyotypes at diagnosis as detected by G-banding. Bone marrow morphological analysis showed that two thirds of the patients had trilineage dysplasia. All but two cases (cases 18 and 22) were classified as erythroleukemia (erythroid/myeloid), according to the WHO classification criteria (Table 1). The clinical course of the patients was poor, with a mean survival of only 4.3 months (range, 1-25 months). To characterize the chromosome profile completely, we performed spectral karyotyping in all cases. The SKY karyotypes are given in Table 1. All data discussed below make reference to the SKY analysis.

Hypodiploidy seems to be a rather common genetic feature of ERL. Thirteen cases (56\%) showed hypodiploid karyotypes. The proportion of hypodiploid cases (excluding cases with only monosomy 7) has been reported (Mitelman et al., 2002) to range between $2 \%$ for M5 and $11 \%$ for M1, with ERL showing a significantly higher ratio of $38 \%$. In our series, which included only de novo cases, $70 \%$ of the cases showed chromosome 5 monosomy or $5 \mathrm{q}$ deletions; trisomy 8 , either alone 
TABLE I. Clinical and Molecular Cytogenetic Description of the Abnormal Clones Found in de Novo ERL Patients Using GTG Banding and SKY Techniques

\begin{tabular}{|c|c|c|c|c|}
\hline $\begin{array}{l}\text { Case } \\
\text { no. }\end{array}$ & $\begin{array}{l}\text { Sexl } \\
\text { age }\end{array}$ & Survival ${ }^{\mathrm{a}}$ & Dysplasia $^{\mathrm{b}}$ & SKY karyotype \\
\hline I & $M / 73$ & 1 & Tri & 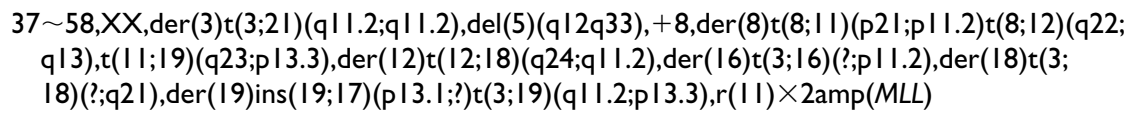 \\
\hline 2 & $M / 77$ & 1 & Tri & $44 \sim 46, X X, \operatorname{del}(5)(q \mid 3 q 33),-7,-19$ \\
\hline 3 & $\mathrm{~F} / 63$ & 5 & Tri & $46 \sim 48, X X, \operatorname{del}(5)(q \mid 3 q 33),+8, \operatorname{der}(I I) t(6 ; 1 I)(p \mid 5 ; ?),-13,-18,+19,+21$ \\
\hline 4 & $\mathrm{~F} / 57$ & 2 & Tri & $44, X Y, t(1 ; 7)(q 32 ; q 32),-7,+8,-9,-13,-17,-20,+21 \times 2$ \\
\hline 5 & $M / 69$ & 3 & Tri & $45 \sim 55, X X,+X,+I,+2, \operatorname{del}(5)(q \mid 3 q 33),+6,+8,+I I,+r(I I) \times 2 a m p(M L L),+I 4,+22$ \\
\hline 6 & $M / 67$ & 5 & Tri & 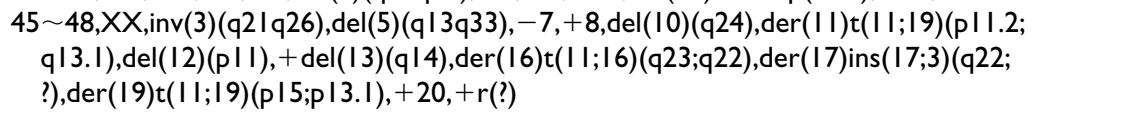 \\
\hline 7 & $M / 68$ & 4 & Ery & $\begin{array}{l}45 \sim 46, Y, \operatorname{der}(X) t(X ; \mid 3)(p 22 . \mid ; q 22), i(3)(q \mid 0), \operatorname{del}(5)(q 22), \operatorname{inv}(6)(p 23 q \mid 2), \operatorname{der}(\mid 3) t(2 ; 9 ; \mid 3)(? ; ? ; \\
\quad q 22), \operatorname{der}(\mid 6) t(I ; \mid 6)(? ; q 2 \mid-22),+|9,-2|\end{array}$ \\
\hline 8 & $M / 65$ & 3 & Tri & $44 \sim 45, X Y, \operatorname{del}(5)(q \mid 3),-7,+8, \operatorname{del}(12)(p \mid 3), \operatorname{der}(16) t(2 ; 16)(? ; q ?),+20$ \\
\hline 9 & $M / 70$ & 4 & Tri & $\begin{array}{l}6 I \sim 65, X Y Y,+I \times 2,+2,+3,+4,+5, \operatorname{der}(5) t(5 ; \mid 4 ; 16)(q|3 ; q| 3 ; \\
\quad ?),+\operatorname{inv}(6)(p 23 q \mid 2) \times 2,+7,+8 \times 2,+16,-19, \operatorname{der}(19) t(19 ; 20)(q \mid 3 . I \\
\quad \text { PII. } 2) \times 2,+2 I \times 2,+22,+\operatorname{der}(22) \operatorname{del}(22)(q \mid 1) \times 2\end{array}$ \\
\hline 10 & $M / 7 I$ & 8 & Tri & 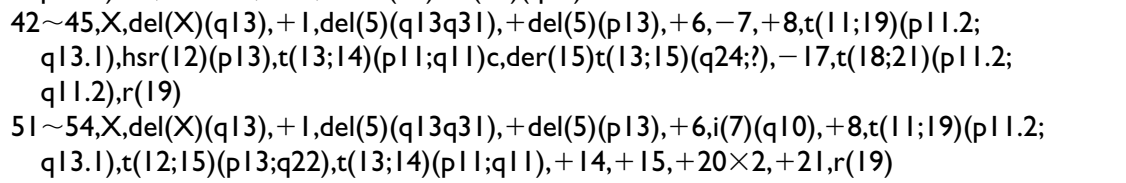 \\
\hline II & $\mathrm{F} / 69$ & I & Tri & $5 \mathrm{I} \sim 52, \mathrm{XX},+8, \operatorname{del}(10)(q 24), \operatorname{del}(I I)(p \mid 5),-3, \operatorname{der}(16) t(7 ; \mid 6)(? ; q 24)$ \\
\hline 12 & $\mathrm{~F} / 76$ & 6 & Ery & $\begin{array}{l}35 \sim 42, \mathrm{XX}, \mathrm{r}(3),-5, \operatorname{der}(7) \mathrm{t}(6 ; 7)(? ; \mathrm{q} 22), \mathrm{t}(7 ; 10)(\mathrm{p} \mid 5 ; \mathrm{q} 22),-9,-10, \operatorname{der}(\mid \mathrm{I}) \mathrm{t}(9 ; \mid \mathrm{I})(\mathrm{p} \mid 2 ; \\
\quad \mathrm{pl5}), \operatorname{del}(13)(\mathrm{q} 22),-17,-18\end{array}$ \\
\hline 13 & $\mathrm{~F} / 59$ & 14 & Tri & $\begin{array}{l}45, X X, \operatorname{der}(1 ; 19)(p 32 ; p \mid 3.1), \mathrm{t}(3 ; 9)(q 21 ; q \mid 3), \operatorname{del}(5)(\mathrm{q} \mid 3 \mathrm{q} 31), \mathrm{t}(14 ; \\
\quad 21)(\mathrm{q}|0, \mathrm{q}| 0),-17,-19,+\mathrm{r}(1 \mid) \mathrm{amp}(M L L)\end{array}$ \\
\hline 14 & $\mathrm{~F} / 72$ & 5 & Ery & $45, X X,-5, \operatorname{der}(7) t(7,9)(q 32 ; q \mid 3), \operatorname{der}(9) t(9,19)(q|3 ; q| 3.1),-\mid 8,+21, d m i n, a m p(c-M Y C)$ \\
\hline 15 & $M / 82$ & I & Tri & $46 \sim 48, X Y, \operatorname{der}(2) t(2 ; 3)(q 31 ; ?),+4,-7,+8$ \\
\hline 16 & $\mathrm{~F} / 69$ & 3 & Tri & $44, X X, t(1 ; 12)(q 42 ; p \mid 3), t(2 ; 15)(q 31 ; q 24), \operatorname{der}(5) \mathrm{t}(5 ; 17)(\mathrm{q} \mid 3 ; q 22), \mathrm{t}(6 ; \mid 8)(\mathrm{q} 27 ; \mathrm{q} 21),-7,-17$ \\
\hline 17 & $\mathrm{~F} / 7 \mathrm{I}$ & 24 & Tri & $46, X X, \operatorname{del}(\mathrm{I})(\mathrm{pl} 3),-7, \operatorname{der}(I \mathrm{I}) \mathrm{t}(\mathrm{I} ; \mathrm{II})(? ; q 23), \operatorname{ins}(12 ; \mathrm{I})(\mathrm{q} 24 ; ?), \operatorname{der}(\mid 4) \mathrm{t}(\mathrm{I} ; \mid \mathrm{I})(? ; q \mid 3),+20$ \\
\hline 18 & $\mathrm{~F} / \mathrm{I}$ & 7 & Eryc & $49, X X, \operatorname{inv}(X)(p 22 . \mid q 13),+5,+8,+18[15]$ \\
\hline 19 & $\mathrm{~F} / 37$ & 25 & Ery & $46, X, t(X ; I I)(q|3 ; p| 5), \operatorname{del}(14)(q 23 q 32)[20]$ \\
\hline 20 & $\mathrm{~F} / 85$ & 7 & $\mathrm{E} / \mathrm{M}$ & $46 \sim 47, X X,-5,+8, \operatorname{del}(20)(q \mid 2)$ \\
\hline 21 & $M / 50$ & 25 & Ery & 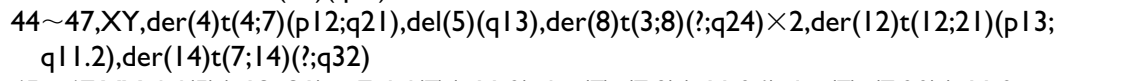 \\
\hline 22 & $\mathrm{~F} / 76$ & 8 & $\mathrm{E} / \mathrm{M}$ & $\begin{array}{l}45 \sim 47, X X, \operatorname{del}(5)(q|3 q 3|),-7, \operatorname{del}(7)(q|| .2), \operatorname{der}(7) t(7 ; 9)(q|| .2 ; ?), \operatorname{der}(7) t(7 ; 20)(q|| .2 ; \\
\quad q \mid I .2), \operatorname{der}(16) t(1 ; \mid 6)(? ; q 22), \operatorname{der}(\mid 8) t(7 ; \mid 8)(q 22 ; q 2 \mid)\end{array}$ \\
\hline 23 & F/7I & 6 & Tri & $46 \sim 47, X X, t(X ; 9 ; 22)(? ; q 34 ; q|| .2),+8, \mathrm{i}(17)(q \mid 0)$ \\
\hline
\end{tabular}

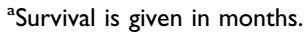

bLineage involvement: Tri, erythroid-myeloid-megakaryoblastic; Ery: erythroid; E/M: erythroid-myeloid.

'Pure erythroid leukemia. M6b type, according to the WHO classification.

or with other abnormalities, was seen in $52 \%$ of the cases; monosomy or $7 \mathrm{q}$ deletions were observed in $43 \%$ of the patients. Taken together, $87 \%$ of the cases displayed aberrations involving chromosome 5 or 8 , and $91 \%$ of the cases demonstrated an abnormality of chromosome 5,7 , or 8 .

Two recent papers have demonstrated that hypodiploidy and loss of genetic material are the most frequent finding in AML with complex karyotypes (Mrozek et al., 2002; Schoch et al., 2002). Those series both included de novo and therapy-related cases; the most frequent whole-chromosome losses were monosomies 7 and 18 , and the most frequent interstitial deletions involved $5 \mathrm{q}, 17 \mathrm{p}, 12 \mathrm{p}$, and 20q. In our series of de novo ERL cases, we observed a nearly identical profile, suggesting a common genetic pattern of chromosomal aberrations in myeloblast proliferation.

Fifty-two rearrangements (excluding deletions) were defined in our series, with a median of 2.3 per case (range, $0-10$ ), of which 13 were balanced translocations. SKY analysis refined the vast majority of structural aberrations. None has been reported in the Mitelman Database (Mitelman et al., 2002) or in the most recently reported ERL cases (Mrozek et al., 2002; Schoch et al., 2002). In fact, 
Figure I. Molecular cytogenetic findings in acute erythroleukemia. A: An inverted DAPI-stained metaphase spread of case 6 with an arrow pointing to the cryptically altered chromosome II. B: Spectral image of the same metaphase cell from case 6 . The arrow indicates the derivative chromosome II from the translocation $\mathrm{t}(\mathrm{I} \mid \mathrm{i} / 9)(\mathrm{pl}|\mathrm{I} 2 ; \mathrm{q}| 3 . \mathrm{I})$. Blue and green colors correspond to chromosomes $I I$ and 19 , respectively. $\mathbf{C}$ : WCP of chromosome 19 (green signal) on a partial metaphase from case 10. Green color corresponds to the genetic material from chromosome 19, which has been translocated onto chromosome II. Additional green signals correspond to normal and derivative chromosome 19. D: FISH assay on case 6 with telomeric probes from the short (green signal) and long (red signal) arms of chromosome 19. Red signals on the translocated chromosome II confirmed the involvement of the long arm of chromosome 19 in $\mathrm{t}(1 \mathrm{I} ; 19)$. A normal chromosome 19 with both red and green signals is also shown. E: FISH assay with the MLL gene probe on a metaphase from case I. The $M L L$ gene probe gives a two-color (green and red) signal, usually seen as a yellow fusion signal. The partial metaphase shows two ring chromosomes (arrows) with multiple (4 to 6) copies of the $M L L$ genes that are seen as multiple spots on the abnormal chromosomes.

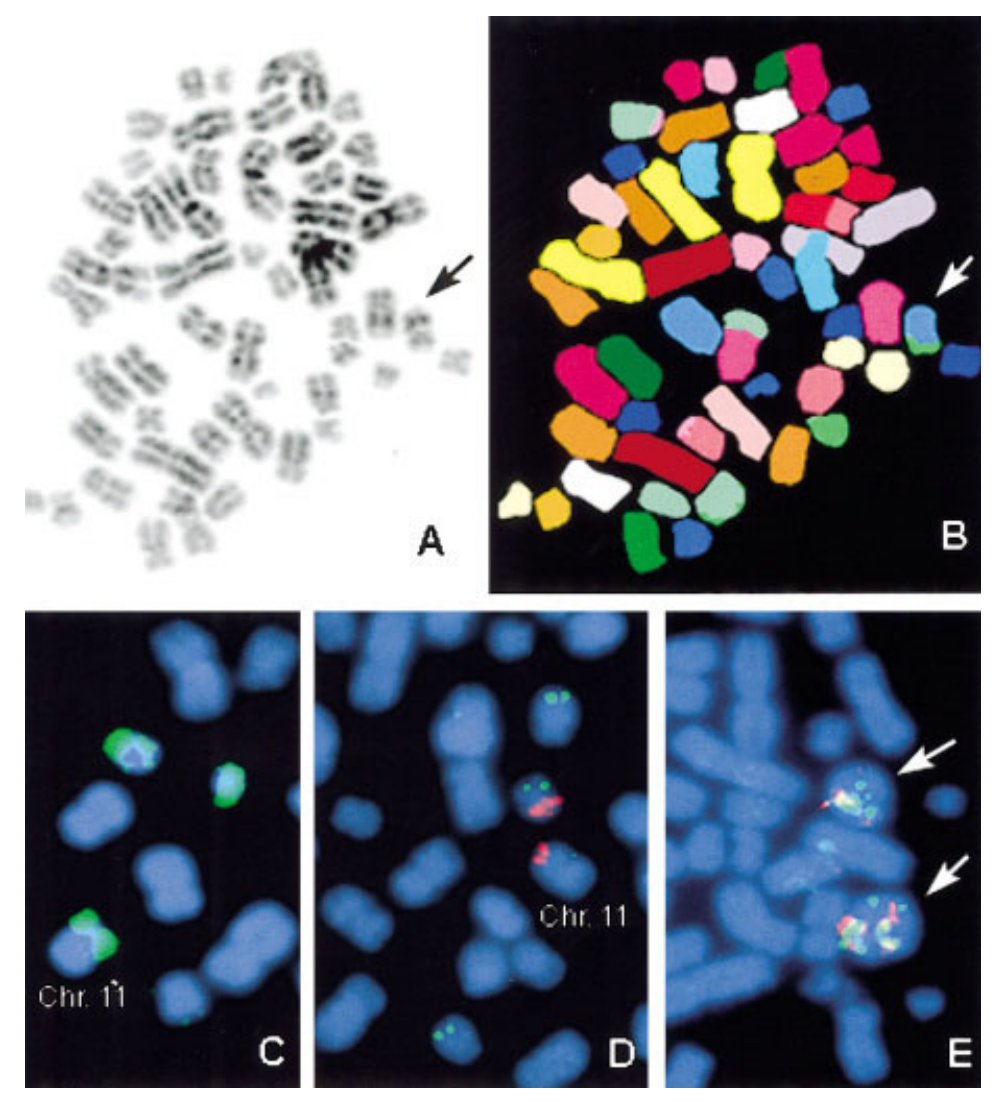

the karyotypes of ERL have generally been characterized by the presence of numerous chromosomal rearrangements, without specific and recurrent breakpoints. Only the $\mathrm{t}(3 ; 5)$ translocation has been seen in several cases of M6 (10 of 378 cases), but the exact breakpoints involved are not identical (Kwong, 1998; Mitelman et al., 2002). We did not find this rearrangement in our series. As in other acute myeloid leukemias with complex karyotypes, unbalanced rearrangements led to the net loss of genetic material in several segments, mainly $5 \mathrm{q}$, $7 \mathrm{q}, 17 \mathrm{p}$, and $12 \mathrm{p}$. Although it has been reported that some $5 q$ or $7 q$ deletions can be redefined as unbalanced translocations, we did not find such deletions.

A novel and cryptic recurrent balanced translocation was found in cases 6 and 10 of our study. The $\mathrm{t}(11 ; 19)(\mathrm{p} 11.2 ; \mathrm{q} 13.1)$ has not been reported previously for any kind of malignancy. The translocation was detected only by SKY, whereas it had been described as a deletion on $11 \mathrm{p}$ by conventional cytogenetics. We characterized the translocation by WCP and FISH hybridizations and used telomeric probes for chromosome 19 (Fig. 1A-D). The lack of sufficient biological material from the patients precludes specific molecular genetic stud- ies; however, both chromosomal regions, 11p11.2 and $19 q 13.1$, harbor genes that regulate the cell cycle or cell proliferation (e.g., KAI1, HPTP eta, MLL2, and others) (Honda et al., 1994; Huntsman et al., 1999; Silver et al., 1999; Verma et al., 1999).

We found three translocations with breakpoints at $11 \mathrm{q} 23$, the chromosomal site of the $M L L$ gene: $\mathrm{t}(11 ; 19)(\mathrm{q} 23 ; \mathrm{p} 13.3), \mathrm{t}(11 ; 16)(\mathrm{q} 23 ; \mathrm{q} 22)$, and $\mathrm{t}(1$; $11)($ ?;q23) in cases 1,6 , and 17 , respectively. By FISH analysis, we detected that MLL was rearranged in these three cases. The first two translocations have been reported in small series of AML-M6 that occurred after exposure to DNAdamaging agents (Groupe Français de Cytogénétique Hématologique, 1984; Moorman et al., 1998). Our cases had no antecedents of such exposure, although, because the $M L L$ gene is recurrently involved in acute leukemia (Rowley, 1998), we analyzed its status by FISH in all our samples. We found that MLL was amplified in the same case 1 and in two additional cases (5 and 13) (Table 1). In all three cases, five to seven copies of $M L L$ were located on a ring chromosome that was identified as being derived from chromosome 11 (Fig. 1E). Five of the 23 cases showed MLL rearrangements, a relatively high frequency that is similar to the fre- 

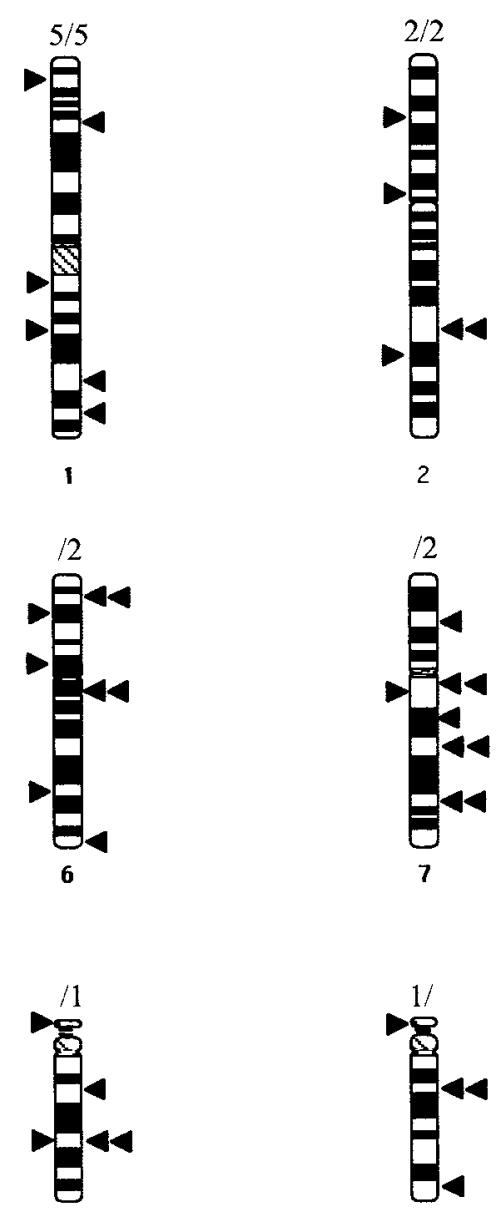

13
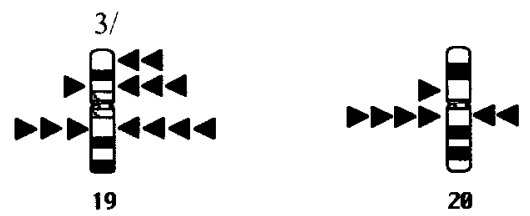
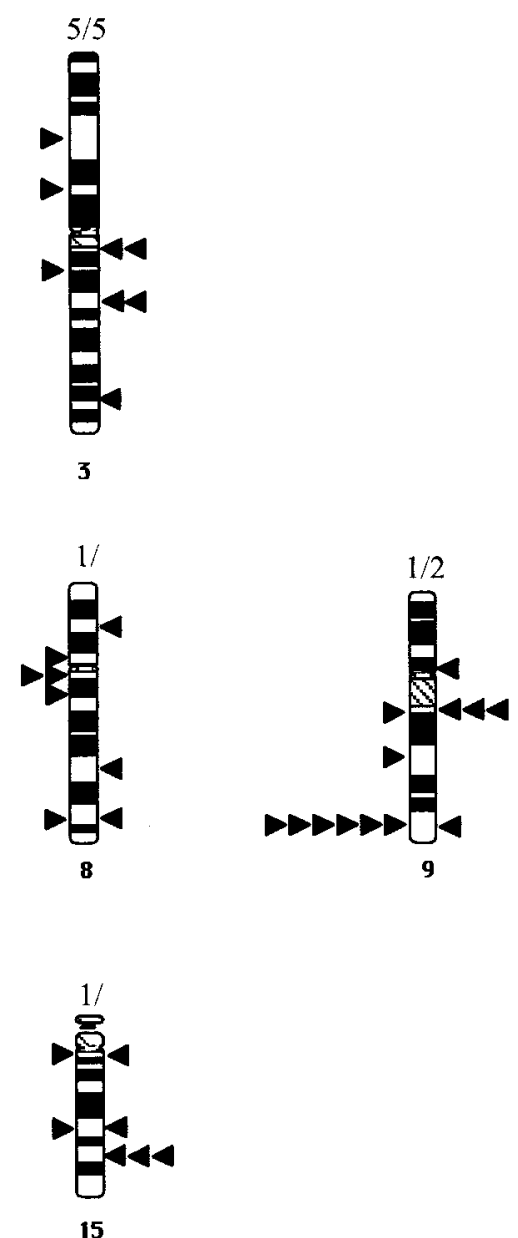

$\rightarrow \underbrace{9}_{21}$
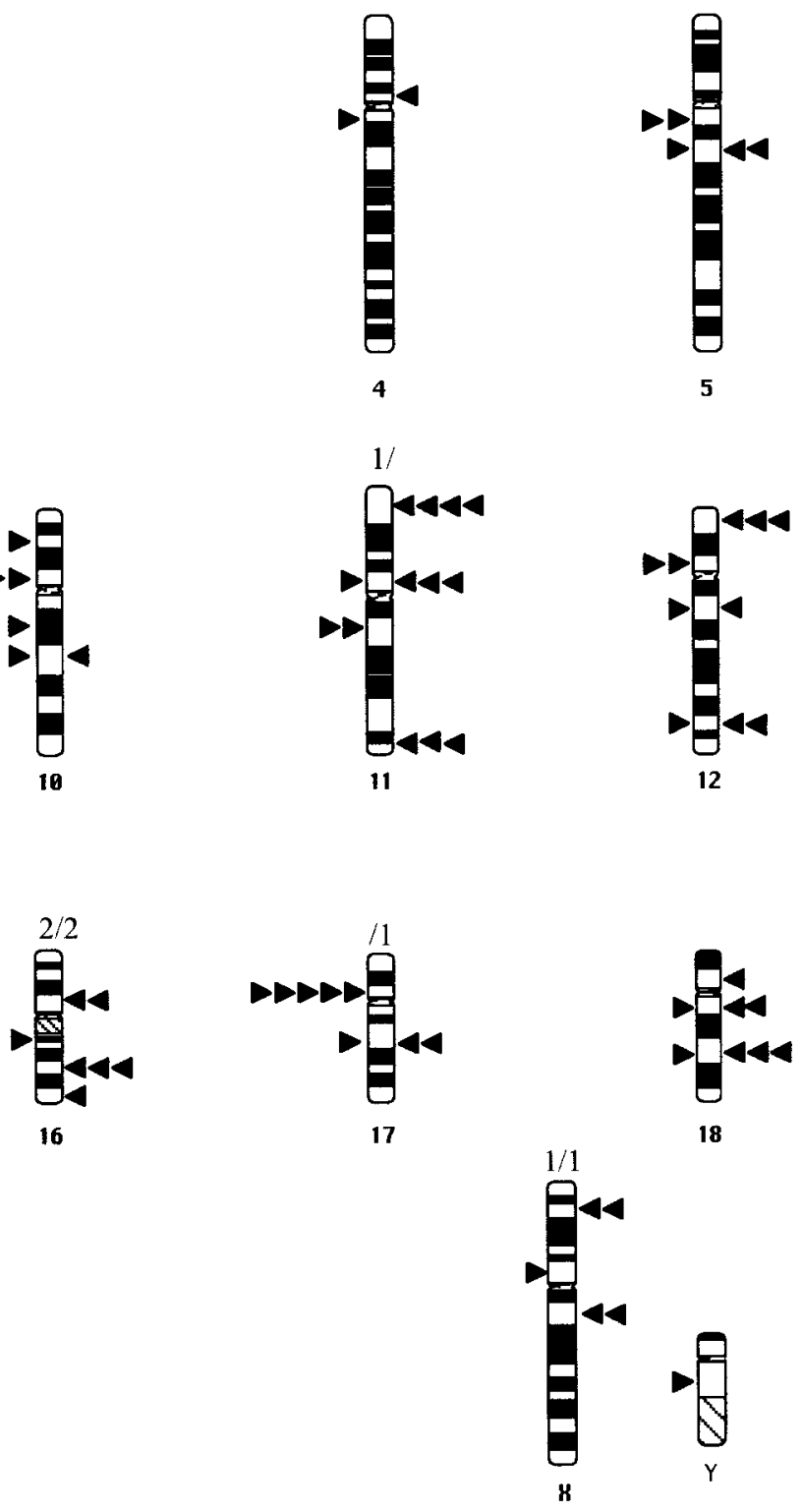
TABLE 2. SKY Karyotype of the Structural Rearrangements of Erythroblastoid Leukemic Cell Lines

\begin{tabular}{|c|c|}
\hline Cell line & SKY karyotype \\
\hline TF-I & 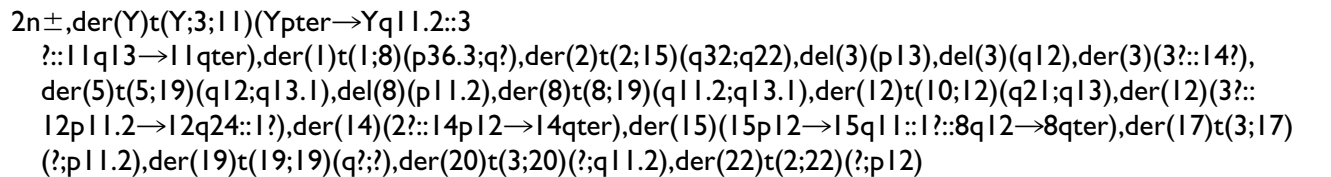 \\
\hline HEL-R & 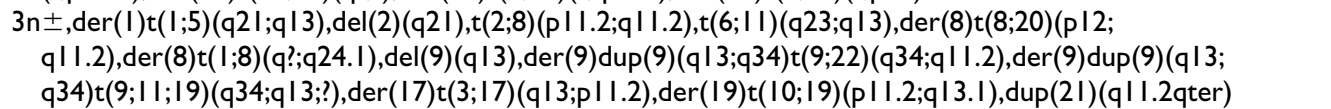 \\
\hline AP2I7 & 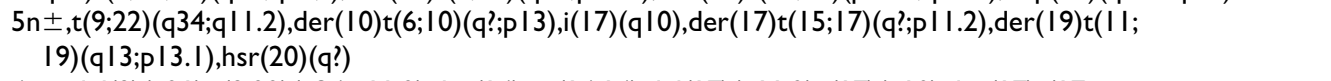 \\
\hline Ku8I2 & 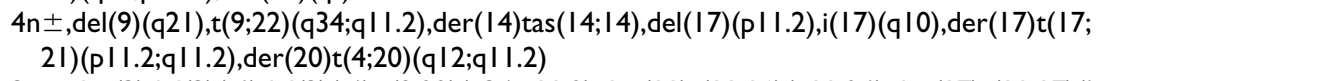 \\
\hline LAMA84 & 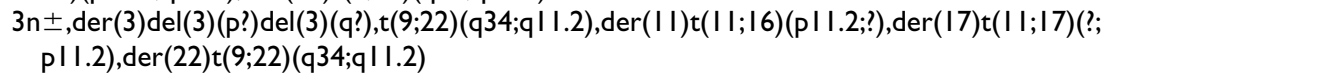 \\
\hline KmoE-02 & 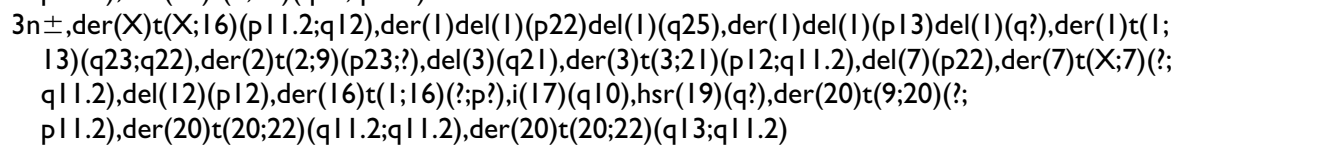 \\
\hline K562 & 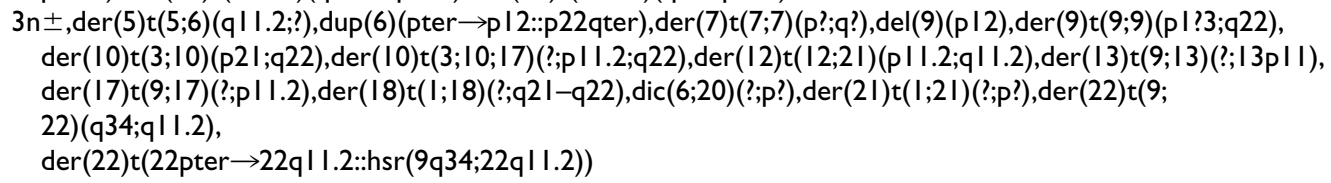 \\
\hline
\end{tabular}

quency found in AML M5a, M5b, or M4. About 40 cases of AML with amplifications of the MLL gene have been documented thus far (Avet-Loiseau et al., 1999; Cuthbert et al., 2000; Michaux et al., 2000; Park et al., 2000; Streubel et al., 2000; Mrozek et al., 2002; Schoch et al., 2002), suggesting its important role in leukemogenesis. Other genomic amplifications were detected: one case with double-minute chromosomes, which were shown to be C-MYC amplifications, and a homogeneously staining region (HSR) on chromosome arm 12p. Neither C-MYG nor MLL amplifications, nor HSRs have been reported previously in patients with ERL.

The cytogenetic rearrangements showed 51 chromosomal breakpoints that were non-randomly distributed (Fig. 2). Chromosomes 11 and 19 were most frequently involved in chromosomal aberrations, clustering 11 and 10\%, respectively, of all of the rearrangements. The most recurrent breakpoints were bands $11 \mathrm{p} 15,19 \mathrm{q} 13.1$, involved in four rearrangements each; and bands $9 \mathrm{q} 13,11 \mathrm{p} 11.2$,

Figure 2. Ideogram showing the breakpoints involved in structural rearrangements in erythroleukemia. Arrowheads to the left of each chromosome indicate breakpoints observed in the cell lines. Right of each chromosome indicates breakpoints observed in patients. Numbers above each chromosome are the number of breakpoints that could not be assigned to a specific band. The left number corresponds to cell lines and the right number corresponds to patient samples. 11q23, 12p13, 15q24, 16q22, 18q21, 19p13.1, and 21q11.2, involved in three rearrangements each. A recent report of the cytogenetic profile of M7 AML (Dastigue et al., 2002), by conventional G-banding, shows that, despite the high complexity of the karyotypes, the distribution of the breakpoints between the ERL and M7 subtypes of AML is rather different both in their location and in their frequency.

Molecular cytogenetic analysis of the erythroid cell lines showed a different pattern (Table 2). Five cell lines were established from $B C R / A B L$ positive cells during the blast crisis phase of CML. Their cytogenetic profile fits this condition: the presence of an extra Philadelphia chromosome and of isochromosome $17 \mathrm{q}$, and trisomy 8 . At the ploidy level, all cell lines but TF-1 were tri- or tetraploid, whereas patient samples were mostly diploid and hypodiploid. Probably these differences were attributable to the late passage status of the cell lines. A comparison of the chromosome breakpoint pattern between patients and cell lines (Fig. 2) shows only a few common sites of recurrent breakpoints: these were $19 q 13.1,20 q 13.1$, and 21q11.2. The remaining breakpoints were distributed according to a different pattern. As for the translocations, only one was recurrent in case 21 and in the K562 cell line, the $\mathrm{t}(12 ; 21)(\mathrm{p} 11.2 ; \mathrm{q} 11.2)$. It was an unbalanced translocation and only the derivative chro- 
mosome 12 was retained in the cell, resulting in loss of 12 p and gain of chromosome 21 material. In general, the available erythroid cell lines are not comparable to the de novo ERL cases, most likely because of their CML-derived origin.

This is the first report of molecular cytogenetics and karyotype features of a large number of cases of de novo erythroid leukemia with a complex karyotype. The use of new molecular cytogenetic techniques demonstrated several interesting features of ERL: (1) Hypodiploidy and multiple unbalanced translocations are very common, with net losses of chromosome material; (2) we have found a novel, cryptic translocation $\mathrm{t}(11 ; 19)$ in two patients; (3) MLL rearrangements, both as translocated or as amplified, are frequent in the absence of exposure to genotoxic agents; (4) the breakpoint analysis pointed to chromosomes 11 and 19 as the most frequently involved. This distribution of the breakpoints shows a different pattern for ERL than for other subtypes of AML. These features suggest a characteristic genetic picture of ERL and helps focus on a more intensive molecular study of this disease.

\section{REFERENCES}

Avet-Loiseau H, Godon C, Li JY, Daviet A, Mellerin MP, Talmant P, Harousseau JL, Bataille R. 1999. Amplification of the 11q23 region in acute myeloid leukemia. Genes Chromosomes Cancer 26:166-170.

Bennett JM, Catovsky D, Daniel MT, Flandrin G, Galton DA, Gralnick HR, Sultan C. 1985. Proposed revised criteria for the classification of acute myeloid leukemia: a report of the FrenchAmerican-British Cooperative Group. Ann Int Med 103:626-629. Cuneo A, Van Orshoven A, Micheaux JL, Boogaerts M, Louwagie A, Doyen C, Dal Cin P, Fagioli F, Castoldi G, Van den Berghe H. 1990. Morphologic, immunologic and cytogenetic studies in erythroleukemia: evidence for multilineage involvement and identification of two distinct cytogenetic-clinicopathologic types. Br J Haematol 75:346-354.

Cuthbert G, Thompson K, McCullough S, Boogaerts M, Louwagie A, Doyen C, Dal Cin P, Fagioli F, Castoldi G, Van den Berghe H. 2000. MLL amplification in acute leukemia: a United Kingdom Cancer Cytogenetics Group (UKCCG) study. Leukemia 14:18851891

Dastugue N, Lafage-Pochitaloff, Pages MP, Radford I, Bastard C, Talmant P, Mozziconacci MJ, Leonard C, Bilhou-Nabera C, Cabrol C, Capodano AM, Cornillet-Lefebvre P, Lessard M, Mugneret F, Perot C, Taviaux S, Fenneteaux O, Duchayne E, Berger R. 2002. Cytogenetic profile of childhood and adult megakaryoblastic leukemia (M7): a study of the Groupe Français de Cytogénétique Hématologique (GFCH). Blood 100:618-626.

Domingo-Claros A, Larriba I, Rozman M, Irriguible D, Vallespi T, Aventin A, Ayats R, Milla F, Sole F, Florensa L, Gallart M, Tuset E, Lopez C, Woessner S. 2002. Acute erythroid neoplastic proliferations. A biological study based on 62 patients. Haematologica 87:148-153.

Goldberg SL, Noel P, Klumpp TR, Dewald GW. 1998. The eythroid leukemias. A comparative study of erythroleukemia (FAB M6) and Di Guglielmos disease. Am J Clin Oncol 21:42-47.

Groupe Français de Cytogénétique Hématologique. 1984. Chromosome analysis of 63 cases of secondary nonlymphoid blood disorders: a cooperative study. Cancer Genet Cytogenet 12:95-104.
Honda H, Inazawa J, Nishida J, Yazaki Y, Hirai H. 1994. Molecular cloning, characterization, and chromosomal localization of a novel protein-tyrosine phosphatase, HPTP eta. Blood 84:4186-4194.

Huntsman DG, Chin SF, Muleris M, Huntsman DG, Chin SF, Muleris M, Batley SJ, Collins VP, Wiedemann LM, Aparicio S, Caldas C. 1999. MLL2, the second human homolog of the Drosophila trithorax gene, maps to $19 \mathrm{q} 13.1$ and is amplified in solid tumor cell lines. Oncogene 18:7975-7984.

Jaffe E, Harris N, Stein H. 2001. WHO classification. Tumours of hematopoietic and lymphoid tissues. Lyon: IARC Press.

Kwong YL. 1998. Translocation $(3 ; 5)(\mathrm{q} 21 ; \mathrm{q} 34)$ in erythroleukemia: a molecular and in situ hybridization study. Cancer Genet Cytogenet 103:15-19.

Mazzella FM, Kowal-Vern A, Shrit MA, Wibowo AL, Rector JT, Cotelingam JD, Collier J, Mikhael A, Cualing H, Schumacher HR. 1998. Acute erythroleukemia: evaluation of 48 cases with reference to classification, cell proliferation, cytogenetics, and prognosis. Am J Clin Pathol 10:590-598.

Michaux L, Wlodarska I, Stul I, Dierlamm J, Mugneret F, Herens C, Beverloo B, Verhest A, Verellen-Dumoulin C, Verhoef G, Selleslag D, Madoe V, Lecomte M, Deprijck B, Ferrant A, Delannoy A, Marichal S, Duhem C, Dicato M, Hagemeijer A. 2000. MLL amplification in myeloid leukemia: a study of 14 cases with multiple copies of 11q23. Genes Chromosomes Cancer 29:40-17.

Mitelman F, editor. 1995. An international system for human cytogenetic nomenclature. Basel: S. Karger.

Mitelman F, Johansson B, Mertens F, editors. 2002. Mitelman database of chromosome aberrations in cancer. May be accessed at http://cgap.nci.nih.gov/Chromosomes/Mitelman

Moorman AV, Hagemeijer A, Charrin C, Rieder H, Secker-Walker LM. 1998. The translocations $t(11 ; 19)(q 23 ; p 13.1)$ and $t(11$; 19)(q23;p13.3): a cytogenetic and clinical profile of 53 patients. European 11q23 Workshop participants. Leukemia 12:805-810.

Mrozek K, Heinonen K, Theli KS, Bloomfield CD. 2002. Spectral karyotyping in patients with acute myeloid leukemia and a complex karyotype shows hidden aberrations, including recurrent overrepresentation of 21q, 11q, and 22q. Genes Chromosomes Cancer 34:137-153.

Olopade OI, Thangavelu M, Larson RA, Mick R, Kowal-Vern A, Schumacher HR, Le Beau MM, Vardiman JW, Rowley JD. 1992. Clinical, morphologic, and cytogenetic characteristics of 26 patients with acute erythroblastic leukemia. Blood 80:2873-2882.

Park JP, Ladd SL, Ely P, Weiner NJ, Wojiski SA, Hawk AB, Noll WW, Mohandas TK. 2000. Amplification of the MLL region in acute myeloid leukemia. Cancer Genet Cytogenet 121:198-205.

Park S, Picard F, Azgui Z, Viguie F, Merlat A, Guesnu M, Leblond V, Dreyfus F. 2002. Erythroleukemia: a comparison between the previous FAB approach and the WHO classification. Leuk Res 26:423-429.

Rowley JD. 1998. Seminars from the University of Minnesota. Chromosome translocations: dangerous liaisons. J Lab Clin Med 132: $244-250$.

Schoch C, Haferlach T, Bursch S, Gerstner D, Schnittge S, Dugas M. Kern W, Loffler H, Hiddemann W. 2002. Loss of genetic material is more common than gain in acute myeloid leukemia with complex aberrant karyotype: a detailed analysis of 125 cases using conventional chromosome analysis and fluorescence in situ hybridization including 24-color FISH. Genes Chromosomes Cancer 35:20-29.

Silver A, Moody J, Dunford R, Clark D, Ganz S, Bulman R, Bouffler S, Finnon P, Meijne E, Huiskamp R, Cox R. 1999. Molecular mapping of chromosome 2 deletions in murine radiation-induced AML localizes a putative tumor suppressor gene to a $1.0 \mathrm{cM}$ region homologous to human chromosome segment 11p11-12. Genes Chromosomes Cancer 24:95-104.

Streubel B, Valent P, Jager U, Edelhauser M, Wandt H, Wagner T, Buchner T, Lechner K, Fonatsch C. 2000. Amplification of MLL gene on double minutes, a homogeneously staining region, and ring chromosomes in five patients with acute myeloid leukemia or myelodysplastic syndrome. Genes Chromosomes Cancer 27:380386.

Verma RS, Manikal M, Conte RA, Godec CJ. 1999. Chromosomal basis of adenocarcinoma of the prostate. Cancer Invest 17:441447. 